\title{
Evaluation of a naturally derived tannin extracts biopolymer additive in drilling muds for high-temperature well applications
}

\author{
Abdul R. Ismail ${ }^{1,2} \cdot$ M. N. A. Mohd Norddin ${ }^{1} \cdot$ Nur A. S. Latefi ${ }^{1}$ Jeffrey O. Oseh ${ }^{1,2,3} \cdot$ Issham Ismail $^{1,2}$. \\ Afeez O. Gbadamosi ${ }^{1,3}$. Augustine J. Agi ${ }^{1}$
}

Received: 22 March 2019 / Accepted: 25 June 2019 / Published online: 29 June 2019

(c) The Author(s) 2019

\begin{abstract}
The formulations of drilling fluids using conventional clays are often faced with difficulties in the control of rheology, filtration and gelation, owing to the flocculation of the clay at the temperature above $250{ }^{\circ} \mathrm{F}$. In this study, tannins were extracted from the bark wastes of Rhizophora Mucronata spp. (RMTE) and used as a deflocculant to formulate water-based muds (WBMs). The efficacy of reducing the gelation and viscosity of WBMs with the extracted RMTE was compared with commercial Modified Desco Tannin (MDT). The RMTE was characterized using Fourier-transform infrared spectroscopy (FTIR). Rheological and filtration control properties tests were conducted on the RMTE and MDT mud samples before and after hot rolling tests at different temperatures of $225^{\circ} \mathrm{F}, 250^{\circ} \mathrm{F}, 275^{\circ} \mathrm{F}$ and $300^{\circ} \mathrm{F}$. FTIR test data indicate the presence of different active functional groups in the RMTE structure, especially the hydroxyl $(-\mathrm{OH})$ groups, which are responsible for the good thinning ability of the RMTE. Experimental data of the WBM after hot rolling tests with $8 \mathrm{~g}$ concentration at $300{ }^{\circ} \mathrm{F}$ show a $43.5 \%$ reduction of plastic viscosity with MDT and 50\% reduction with RMTE. With a concentration of $2 \mathrm{~g}$, the yield point of the WBM with commercial MDT and locally derived RMTE at $225^{\circ} \mathrm{F}$ before hot rolling tests reduced by $50 \%$ and $57.1 \%$, respectively. Furthermore, the addition of RMTE and MDT to the WBM reduced the filtrate volume and the gel strength. The experimental data indicate that the RMTE shows better deflocculating performance compared to that of the MDT, illustrating the need for its application in WBMs for high-temperature wells.
\end{abstract}

Keywords High temperature $\cdot$ MDT $\cdot$ Rheological properties $\cdot$ RMTE $\cdot$ Tannin extracts

$\begin{array}{ll}\text { Abbreviations } \\ \text { API } & \text { American petroleum institute } \\ \text { CTE } & \text { Condensed tannin extracts } \\ \text { FCT } & \text { Filter cake thickness } \\ \text { FL } & \text { Filtrates loss volume } \\ \text { FRIM } & \text { Forest Research Institute Malaysia } \\ \text { FTIR } & \text { Fourier-transform infrared spectroscopy } \\ \text { GS } & \text { Gel strength }\end{array}$

M. N. A. Mohd Norddin

anam@utm.my

1 Department of Petroleum Engineering, School of Chemical and Energy Engineering, Universiti Teknologi Malaysia, 81310 Johor Bahru, Malaysia

2 Malaysia Petroleum Resource Corporation Institute for Oil and Gas (MPRC-UTM), Universiti Teknologi Malaysia, 81310 Johor Bahru, Malaysia

3 Department of Chemical and Petroleum Engineering, College of Engineering, Afe Babalola University, P.M.B. 5454, Ado-Ekiti, Ekiti State, Nigeria
HPHT High pressure high temperature

HTE Hydrolysable tannin extracts

MDT Modified Desco Tannin

PV Plastic viscosity

RBF Round-bottom flask

RMB Rhizophora mucronata barks

RMTE Rhizophora mucronata tannin extracts

SI Stiasny index

TE Tannin extracts

WBMs Water-based muds

YP Yield point

\section{Introduction}

Over the years, water-based muds (WBMs) and oil-based muds (OBMs) have been widely used to produce oil and gas wells (Sayindla et al. 2017; Oseh et al. 2018; Zhong et al. 2019; Nanthagopal et al. 2019). Owing to the lower environmental effect and operating cost, WBMs are extensively 
used (Fujii 2017; Sayindla et al. 2017; Oseh et al. 2019a, b; Boyou et al. 2019). However, as the well gets deeper, hotter and longer, the WBMs additives become prone to degradation, which often affects their rheological stability (Amani et al. 2012). Therefore, drilling operators have been tasked to use appropriate drilling fluid additives and technologies with innovative methods to withstand high-temperature wells and changing downhole conditions for optimized well economics. The sodium bentonite that is mainly used to add rheology and filtration control characteristics to conventional WBMs often starts to flocculate at temperatures nearing or above $250^{\circ} \mathrm{F}$ (Amani et al. 2012). These drastically affect the performance of WBMs containing bentonite particles for high-temperature wells. An important property of drilling mud particles is their cohesive nature that differentiates them from non-cohesive solids, such as drilled cuttings or sand particles (Altun et al. 2015; Choo and Bai 2015). Bentonite particles in aqueous solution can stick together (flocculate or coagulate) due to van der Waals forces and can turn into aggregates or flocs (Kelessidis 2017; Elochukwu et al. 2017; Oseh et al. 2019b).

Flocculation takes place when clay platelets are electrically attracted to each other (Mahmoud et al. 2017). Three significant conditions can induce flocculations of drilling muds. They are: (1) high amount of active solids, such as clays or barite, (2) increased well depth and (3) high amount of soluble calcium or electrolytes, such as salts which are often regarded as the key source of flocculation (Moslemizadeh et al. 2015; Oseh et al. 2019b). These salts may originate from saltwater flows, make-up water, massive salt sections, salt stringers and commercial sources (AbuJdayil 2011). Sodium bentonite has a molecular formula of $\mathrm{Al}_{2} \mathrm{H}_{2} \mathrm{Na}_{2} \mathrm{O}_{13} \mathrm{Si}_{4}$ with a molecular weight of $422.286 \mathrm{~g} / \mathrm{mol}$. When the content of positive sodium ion $\left(\mathrm{Na}^{+}\right)$is increased up to $1 \%$, water will turn out to be more positively charged. This charge will be stronger than the ionized protective layer that covers the clay platelets (Choo and Bai 2015). When the positive edge aluminium ions $\left(\mathrm{Al}^{3+}\right)$ combine with the oxygen face, the edge-to-face movement will be accelerated. This often results in a dramatic increase in viscosity and increased loss of drilling fluid (Choo and Bai 2015). Flocculation or coagulation modifies the properties of the mud and causes colloids to aggregate and forms sediments in the mud (Abu-Jdayil 2011). This effect contributes to the modification in the behaviour of clay particles and causes resistance to the fluid flow. The mud becomes excessively gel-like, which lead to stuck pipe, and increasing viscosity that need more pump output to circulate (Mahmoud et al. 2017). Therefore, the addition of deflocculants to the drilling mud can contribute to controlling mud flocculation, and thus reduce the mud viscosity.

The addition of solid additives, such as barite or clay materials, increases the rheology of the drilling mud, especially the plastic viscosity (Kelessidis 2017; Oseh et al. 2018). Several recent studies indicate that locally sourced deflocculants (thinners or deflocculating agent) are effective in the control of clay flocculation and gelation of the drilling mud (Moslemizadeh et al. 2016; Basyuni et al. 2018; Ghazali et al. 2018a, b; Oseh et al. 2019a, b). In drilling mud, deflocculants prevent mud flocculation or gelation by controlling the rheology of the dispersed mud samples (Moslemizadeh et al. 2016). The control of mud rheological properties will help to reduce filtrate flux and ensure formation of a low-permeable filter cake at the wellbore. It will also help to prevent related wellbore drilling problems (Barry et al. 2015; Oseh et al. 2019b).

According to the reports of Neshat and Shadizadeh (2016), materials commonly used as deflocculants in WBMs are classified as plant tannins having a chemical formula $\mathrm{C}_{76} \mathrm{H}_{52} \mathrm{O}_{46}$ with a molecular weight of $1701.206 \mathrm{~g} /$ mol. Other deflocculants, such as lignosulfonates, have a chemical formula of $\mathrm{C}_{20} \mathrm{H}_{24} \mathrm{Na}_{2} \mathrm{O}_{10} \mathrm{~S}_{2}$ and molecular weight of $534.502 \mathrm{~g} / \mathrm{mol}$, while low-molecular-weight water-soluble henna has a chemical formula of $\mathrm{C}_{10} \mathrm{H}_{6} \mathrm{O}_{3}$ and molecular weight of $174.15 \mathrm{~g} / \mathrm{mol}$ (Moslemizadeh et al. 2016; Basyuni et al. 2018). Tannins are light-tobrown or reddish amorphous granular powder that are obtained chemically and are also derived locally from plants (Basyuni et al. 2018). Commercially, it is often referred to as tannic acid. Tannins or tannoids are normally found in the barks, woods, root, fruits and leaves of many plants, particularly phenolic compounds having enough hydroxyl $(-\mathrm{OH})$ groups. Tannins when dissolved in water form colloidal solutions, but the nature of their solubility depends on their degree of polymerization (Wilson and Hatcher 1988). They are also soluble in alcohol and acetone and are introduced to carboxyl groups to build strong network structures with different macromolecules (Neshat and Shadizadeh 2016). They can also be derived locally from Rhizophora Apiculata traditionally called Bakau Minyak in Malaysia (Ghazali et al. 2018a, b).

Bakau Minyaks are also referred to as red mangroves. They originated from Rhizophora family, which is a gene of tropical mangrove trees and medicinal plants. These plants are vastly available in East and South-East Asia, such as Malaysia, Singapore and Thailand (Wilson and Hatcher 1988; Afidah 2005). Reports from the Forest Research Institute Malaysia (FRIM) revealed that Bakau minyak barks contain significant amounts of tannins, which is, however, subject to the method of extraction and type of solvents used (Sukardjo 1987). Rhizophora mucronata and Rhizophora mangle are common representatives of the Rhizophora family (Basyuni et al. 2018; Ghazali et al. 2018a, b, Vigneswaran et al. 2018; Maricusa et al. 2018). Locally derived tannin-based Rhizophora mucronata is abundant in soft tissues form, such as leaves, needles and barks wastes 
(Vigneswaran et al. 2018). Rhizophora mucronata species contain high proportions of tannin extracts (TE) (Vigneswaran et al. 2018; Basyuni et al. 2018).

Tannin extracts derived from Rhizophora mисronata species are divided into two forms: condensed tannin extracts (CTE) and hydrolysable tannin extracts (HTE) (Ping et al. 2011; Markom et al. 2007). In the former, benzene nuclei are combined with the larger complex through carbon linkages (Ping et al. 2011), while they combine with oxygen atoms in the latter (Markom et al. 2007). CTE are polymers and oligomers of three-ring flavanols, while HTE are also called gallic acid units (Pérez et al. 2017; Vigneswaran et al. 2018; Basyuni et al. 2018). CTE cannot be hydrolyzed by enzymes or acids, but could be condensed easily to lower-molecularweight tannins (Pérez et al. 2017). HTE decompose in water, with which they react to produce other useful products, such as sugar, protocatechuic acid and garlic acid (Markom et al. 2007). Gallo-tannin is the best-known HTE, which can be extracted by the treatment of nut-gall with organic solvents or water (Markom et al. 2007).

Modified tannins are widely used commercial deflocculants for drilling fluids at high-temperature conditions (Zhang and Dai 1999). Plant barks contain higher amounts of tannins than any other part of the plant (Negm et al. 2015; Pérez et al. 2017). The tannin-based plant sources are Quebracho, Chestnuts, Mimosa and Acacia species (Gaugler and Grigsby 2009; Yunitaa et al. 2016). For drilling purposes, Modified Desco deflocculant is $80 \%$ of commercial deflocculants, which is mainly derived from Quebracho species and Acacia species (Elgailani and Ishak 2016; Ghazali et al. 2018a, b). It is a proprietary tannin-based product often used in drilling mud to decrease gel strength, yield point and viscosity. However, with the deeper drilling depth and highertemperature wells, Desco deflocculant cannot effectively reduce viscosity due to high amount of suspended solids in drilling muds (Annis and Smith 1996; Gaugler and Grigsby 2009).

Modified Desco Tannin deflocculants are mostly imported and treated with chemicals before their applications, and these increase their operating cost, which limits their general application for drilling fluids. Thus, they are less environmentally friendly compared with locally derived deflocculant such as Rhizophora mucronata species (Ghazali et al. 2018a; Vigneswaran et al. 2018; Basyuni et al. 2018). With increasing strict environmental regulations prohibiting the use of chemicals that have adverse effects on the environment, the development of tannin-based deflocculant from naturally derived local species will be a viable option for substituting commercial Desco tannin. Therefore, this study used tannin extracts derived from Rhizophora mucronata (RMTE) (Bakau minyak) barks wastes to control the rheology, filtration and gelation of WBMs resulting from the flocculation of bentonite clay at four different temperatures of $225^{\circ} \mathrm{F}, 250^{\circ} \mathrm{F}, 275^{\circ} \mathrm{F}$ and $300^{\circ} \mathrm{F}$. The performance of the RMTE in WBMs was compared with that of commercial Modified Desco Tannin (MDT)-based deflocculant under different temperatures. FTIR measurement was conducted to identify the functional groups responsible for the thinning effect of the extracted RMTE deflocculant.

\section{Experimental details}

\section{Materials}

Tannins were extracted from Malaysian species of Rhizophora mucronata (Bakau minyak) bark wastes. The extracted tannins were acquired from a local charcoal production company (Kuala Sepetang, Malaysia). The industrial-grade Desco deflocculant shown in Fig. 1 was obtained from Bri-Chemical Supplier Corporation (Denver, Colorado, USA). Analytical-grade concentrated sulphuric acid $\left(\mathrm{H}_{2} \mathrm{SO}_{4}\right)$, formaldehyde, ethanolamine, toluene, acetone, anhydrous methanol, potassium iodate, hydrochloric acid $(\mathrm{HCl})$ and ammonium acetate were acquired from SigmaAldrich (M) (Sdn. Bhd., Malaysia). These materials were used in the extraction process.

\section{Methods}

Figure 2 shows the flow process used to extract tannins from Rhizophora mucronata, drilling mud formulations and property evaluation.

\section{Tannin extraction from Rhizophora mucronata bark wastes}

Soxhlet extraction method was used to extract tannin from the Rhizophora mucronata bark (RMB) wastes, and the

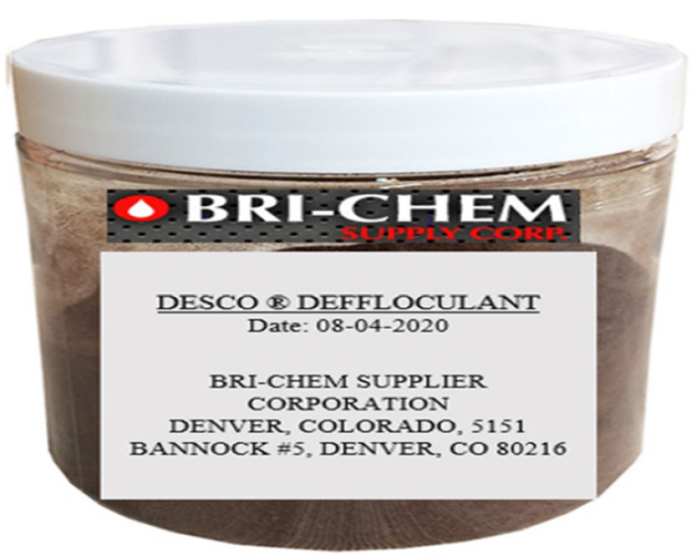

Fig. 1 Commercial Desco deflocculant 


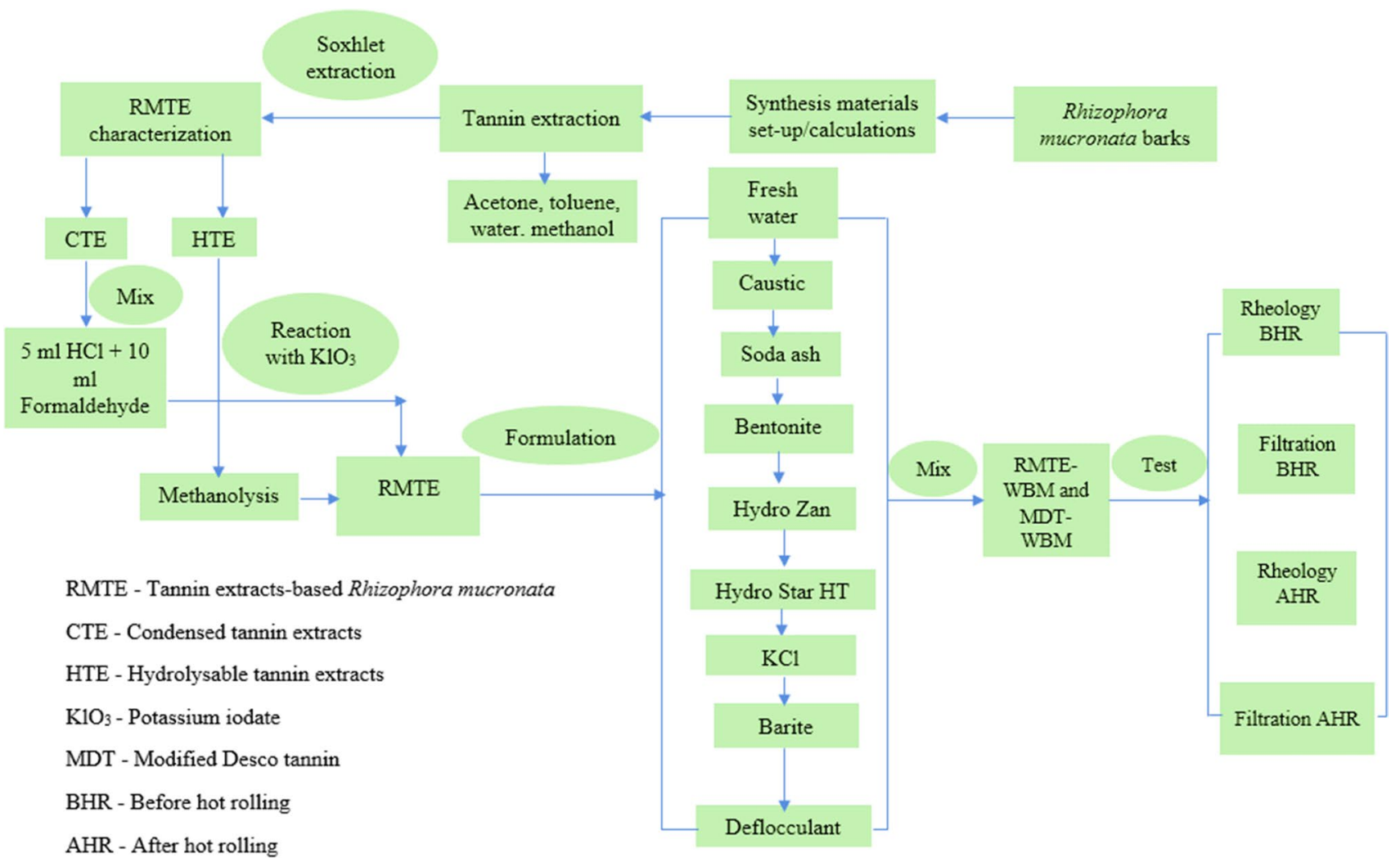

Fig. 2 Flow process used to utilize the production and properties performance of RMTE and MDT-based drilling muds

Fig. 3 a Extraction of tannins from RMB wastes placed in the thimble; $\mathbf{b}$ draining of the extracted tannins
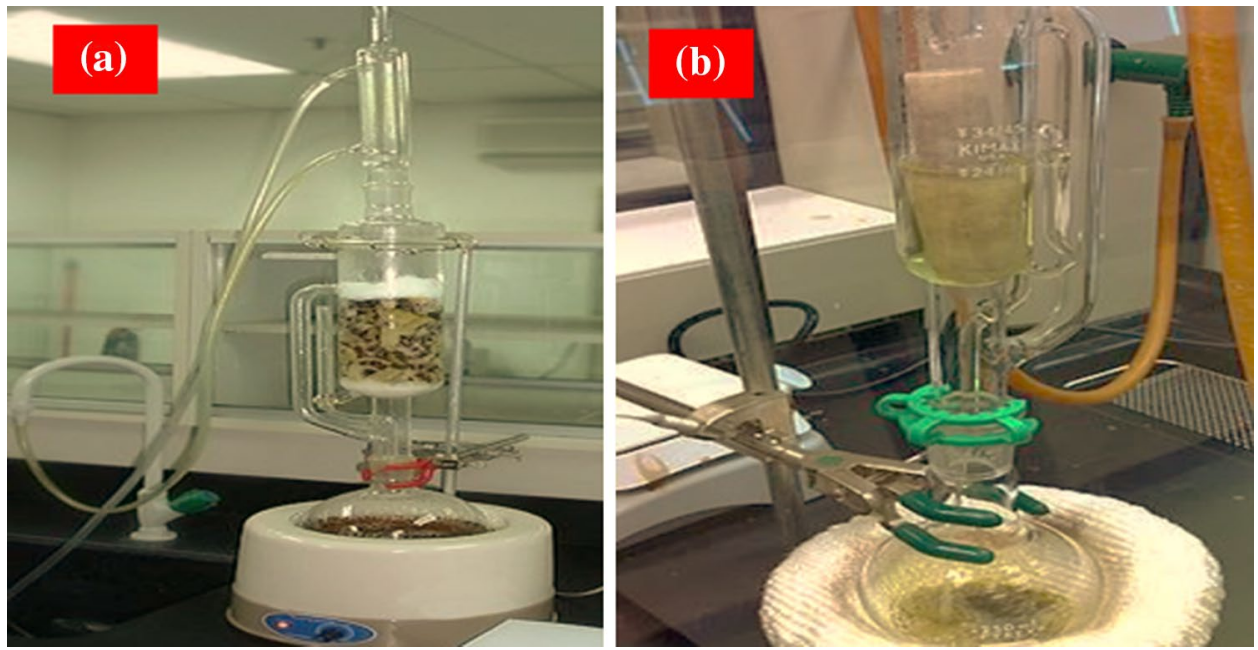

experimental extraction process used is shown in Fig. 3. The standard Soxhlet extractor (BUCHI Laboratory technique, Model B-811, China) was used with different concentrations of hot water as the solvent. In brief, tannin extracts were derived from the bark wastes of Rhizophora mисronata (Bakau minyak) tree (31-33 years old, 15-17 m high and 55-57 cm diameter) from a local charcoal production industry in Kuala Sepetang, Malaysia, and was processed in
FRIM. They were air-dried to a moisture content of about $12-14 \%$ and sliced into small chips. The sample of the RMB plant was ground using Wiley mill into a powdered form and was filtered with a $0.5-\mu \mathrm{m}$ mesh. Their moisture contents were maintained at $10 \%$ and stored. Twenty-five grams of the milled RMB sample was weighed into thimbles. The thimble was placed into the Soxhlet extractor chamber, and a measured volume concentration $(\mathrm{ml})$ of the solvent was 
added into a round-bottom flask (RBF). Three different amounts of $9 \mathrm{ml}, 13 \mathrm{ml}$ and $23 \mathrm{ml}$ of hot water were added for each $25 \mathrm{~g}$ of the milled RMB sample. The extraction solvent was allowed to boil for $3 \mathrm{~h}$ at $212{ }^{\circ} \mathrm{F}$ and $14.7 \mathrm{psi}$. The extracts were collected after $3 \mathrm{~h}$, while the heating of the solvent vessel was continued for another $3 \mathrm{~h}$. The tannin solution was collected after the 3-h heating and was placed in the rotary vacuum evaporator, heated again at $176^{\circ} \mathrm{F}$ until the solution dries up leaving only the residue in the RBF. The weight of the RBF was measured and recorded. The extraction experiment was repeated three times for each solvent (toluene, acetone, methanol and water) at equal weight of RMB to identify the solvent with the optimum yield of tannin. The obtained extracts yields were measured, and the yields of the solvent with the optimum extractions of tannins were selected and used to produce more of the tannins for this study. Extracted RMB wastes are shown in Fig. 4a-c.

\section{Characterization of RMTE powder}

The characterization of RMTE sample was conducted through quantitative test to evaluate the extract yield and Stiasny index (SI) of tannins for CTE, while methanolysis reaction with potassium iodate $\left(\mathrm{KIO}_{3}\right)$ was used to identify the HTE. The functional groups in the RMTE were examined using Fourier-transform infrared spectroscopy (FTIR 8400, Shimadzu, China). The RMTE samples were ground and pressed into pellets with $\mathrm{KBr}$ powder for the FTIR examination in the frequency range of $4000-400 \mathrm{~cm}^{-1}$.

\section{Extract yield of CTE}

RMB tannin extracts were placed in a beaker of measured weight. They were maintained in an oven at a temperature of $221 \pm 2{ }^{\circ} \mathrm{F}$. The extracted tannins were cooled in a desiccator and measured. The sample was reacted with $5 \mathrm{ml} \mathrm{HCl}$ and $10 \mathrm{ml}$ formaldehyde $(1: 2 \mathrm{v} / \mathrm{v})$ mixture for $3 \mathrm{~h}$ to enable the precipitate (i.e. the solute) to dissolve in the $1: 2 \mathrm{v} / \mathrm{v}$ $\mathrm{HCl}$-formaldehyde solvent mixture. The resulting product (precipitated solution) was sieved through a filter paper and washed with hot distilled water. The precipitate was air-dried at a moisture content of $10 \%$ and weighed again after drying. The process was repeated thrice, and the average yield per cent was calculated. The yield per cent of the RMTE sample was evaluated using Eq. (1) as follows:

Yield percent $(\%$ yield $)=\frac{\text { Total dried }- \text { extracts weight }}{\text { Weight of oven dried sample }}$

\section{Stiasny indicator of CTE}

Reactive tannin content is best represented with the Stiasny number, defined as a quantitative approximation of the overall polyphenols in tannin. The Stiasny index (SI) of RMTE sample was obtained using Eq. (2) as follows:

Stiasny index $(\mathrm{SI})(\%)=\frac{\text { Weight of precipitate }}{\text { Weight of dried }- \text { extracts used }}$

\section{Methanolysis and pH adjustment of HTE}

The HTE in the barks of the Rhizophora mucronata tree was identified following a previous research (Makkar 2003). About $25 \mathrm{mg}$ samples of dried RMTE were measured into 20-ml Pyrex screw top tubes by Teflon cap liners. In the methanolysis reaction, the tube top part served as a condenser and as such smaller tubes could not be replaced. Prior to the addition of $2.0 \mathrm{ml}$ methanol and $18 \mathrm{M}$ concentrated sulphuric acid $(200 \mu \mathrm{l})$, the actual weight of the RMTE sample was recorded. The caps were firmly secured to avoid evaporation of solvent during heating. Samples were put in a heating mantle earlier maintained at $212^{\circ} \mathrm{F}$ and were reacted at $212{ }^{\circ} \mathrm{F}$ for $20 \mathrm{~h}$. The tabletop was used to centrifuge the samples. The supernatant obtained was quantitatively moved to a graduated cylinder of $5.0 \mathrm{ml}$, and the methanolysis tube was washed thrice with distilled water and centrifuged again as required. The volume was regulated to $3.0 \mathrm{ml}$ with distilled water, and ethanolamine of four $50 \mu \mathrm{l}$ aliquots was added and was mildly stirred. Five hundred microlitres of 3.7 $\mathrm{M}$ ammonium acetate was added to the RMTE sample,
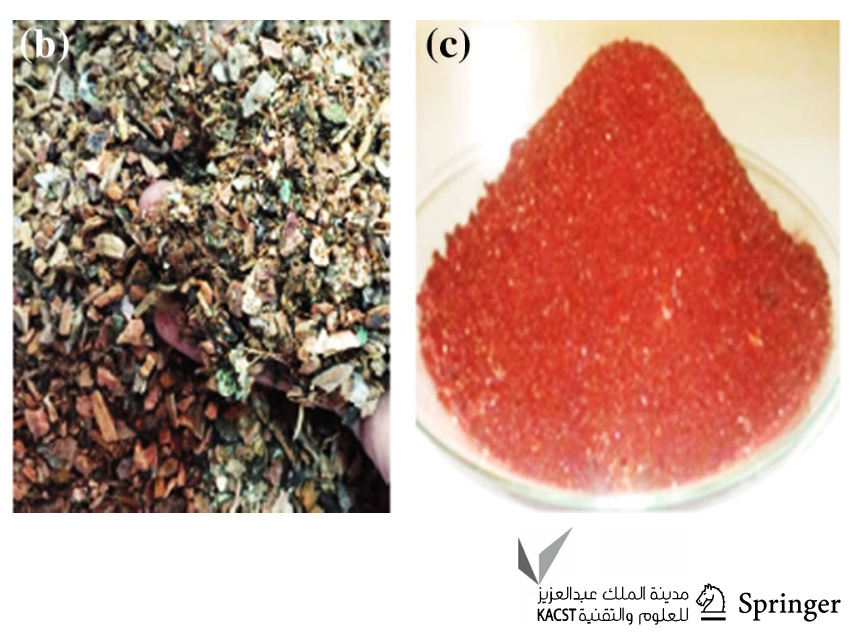

Fig. 4 a RMB from Kuala Sepetang, $\mathbf{b}$ ground RMB and c processed RMB in powdered form

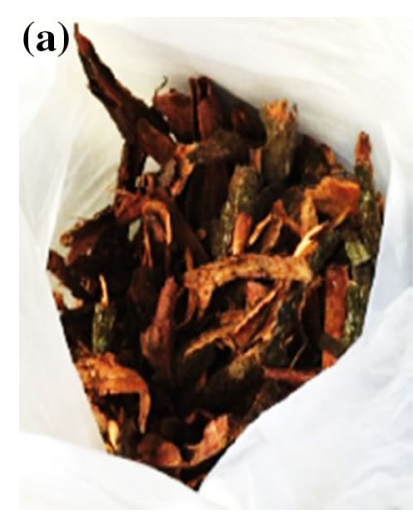


and the $\mathrm{pH}$ was regulated to 5.5. The $\mathrm{pH}$ control was cautiously done as the final volume and $\mathrm{pH}$ were very important to the positive attainment of the method. The sample was brought to a final volume of $4.0 \mathrm{ml}$ with distilled water after the $\mathrm{pH}$ solution and the sample have been thoroughly mixed.

\section{Reaction with $\mathrm{KIO}_{3}$}

Approximately $80 \mu 1$ of the RMTE sample was dispensed into a 2-ml micro-centrifuge tube. The adjusted $\mathrm{pH}$ blank reagent, which was prepared by treating a mixture of $2 \mathrm{ml}$ methanol and $20 \mu \mathrm{l}$ concentrated sulphuric acid, is added to bring the sample volume to $100 \mu$ l. Three hundred and fifty microlitres of water and methanol $(1000 \mu \mathrm{l})$ were added and vortexed. The tube was tightly capped and placed in $86-\mathrm{F}$ water baths. A background mixture similar to the reaction sample was prepared by substituting $350 \mu$ of water with $350 \mu \mathrm{l}$ of $0.3 \mathrm{~N} \mathrm{HCl}$. After adding and diluting the background mixture and the reaction samples, the $\mathrm{KIO}_{3}$ was added at time intervals. Five per cent (w/v) of $40 \mu \mathrm{KIO}$ was added to each sample. The sample was capped, vortexed and regulated to $86-\mathrm{F}$ water baths. At $50 \mathrm{~min}$, after the addition of $\mathrm{KIO}_{3}$ to the sample, its absorbance at $525 \mathrm{~nm}$ was recorded and the per cent HTE was calculated using Eqs. (3) and (4).

Sample absorbance $(\mathrm{nm})=0.0132 \times W+0.0701$

Percent HTE $(\%)=\frac{\text { Weight of tannin }(\mu \mathrm{g})}{0.02} \times 100$

where $W$ is the weight of tannins in microgram $(\mu \mathrm{g})$.

\section{Drilling mud formulations}

For one laboratory barrel (one-gram mass), equivalent to $350 \mathrm{ml}$ of WBM, the water-based mud formulation followed the ascending order. Table 1 shows the compositions and functions of each of the additives used to formulate the WBMs following the API-recommended practice for field testing water-based drilling fluids (API RP 13B-1 2017).
The base mud was formulated to achieve a density of 12 ppg (pounds per gallon). All the additives were mixed using Hamilton beach multi-mixer. The RMTE-based WBM was formulated by adding six different mass concentrations of $2 \mathrm{~g}, 4 \mathrm{~g}, 6 \mathrm{~g}, 8 \mathrm{~g}, 10 \mathrm{~g}$ and $12 \mathrm{~g}$ of the RMTE, equivalent to $350 \mathrm{ml}$ of drilling fluids to the WBM. The MDT-based WBM was formulated with the same mud composition and procedure using $2 \mathrm{~g}, 4 \mathrm{~g}, 6 \mathrm{~g}, 8 \mathrm{~g}, 10 \mathrm{~g}$ and $12 \mathrm{~g}$ of the MDT. Henceforth, the use of the term "concentration(s)" indicates the amount of additive (in gram) added into $350 \mathrm{ml}$ of the formulated water-based mud.

\section{Rheological and filtration properties tests}

Fann Viscometer, model 35 (Fann Instrument, Company, Houston, Texas, USA), was used to measure the rheological behaviour of the mud samples before hot rolling test at four different temperatures of $225^{\circ} \mathrm{F}, 250^{\circ} \mathrm{F}, 275^{\circ} \mathrm{F}$ and $300^{\circ} \mathrm{F}$. The API filtrate loss volume (API FL) was tested with the Fann API filter press at $100 \mathrm{psi}$ and room temperature. Plastic viscosity (PV) and yield point (YP) were computed from the dial reading results of $600 \mathrm{rpm}$ and $300 \mathrm{rpm}$ by using Eqs. (5) and (6). The initial and 10-min gel strengths (GS) were also measured.

$\mathrm{PV}(\mathrm{cP})=\theta_{600}-\theta_{300}$

$\mathrm{YP}\left(\mathrm{lb} / 100 \mathrm{ft} t^{2}\right)=\left(\theta_{300}-\mathrm{PV}\right)$

\section{Thermal stability test}

The thermal properties of all the formulated drilling mud samples were measured after hot-rolling treatment for $16 \mathrm{~h}$ in a 4-roller oven under different temperatures of $225^{\circ} \mathrm{F}$, $250{ }^{\circ} \mathrm{F}, 275^{\circ} \mathrm{F}$ and $300^{\circ} \mathrm{F}$. The rheological and filtration properties of the RMTE and MDT were compared using the concentrations of $2 \mathrm{~g}, 8 \mathrm{~g}$ and $12 \mathrm{~g}$. The PV, YP, initial and 10-min GS of all the mud samples were again measured using Fann viscometer, model 35, according to the API recommendations (API RP 13B-1 2017). Fann high-pressure high-temperature (HPHT) filter press, series 387 (Fann
Table 1 Water-based mud formulation for laboratory scale, equivalent to 1 lab. bbl

\begin{tabular}{llll}
\hline Additives & Units & Functions & WBM \\
\hline Fresh water & $\mathrm{ml}$ & Base fluid & 250.4 \\
Caustic soda $(\mathrm{NaOH})$ & $\mathrm{g}$ & $\mathrm{pH}$ control agent & 0.30 \\
Soda ash $\left(\mathrm{Na}_{2} \mathrm{CO}_{3}\right)$ & $\mathrm{g}$ & Hardness control agent & 0.25 \\
Sodium bentonite & $\mathrm{g}$ & Viscosifier and filtration control agent & 30 \\
Hydro Zan & $\mathrm{g}$ & Rheology modifier & 0.8 \\
Hydro Star HT & $\mathrm{g}$ & Filtration agent and rheology modifier & 5 \\
Potassium chloride $(\mathrm{KCl})$ & $\mathrm{g}$ & Shale stabilizer and water activity control & 20 \\
Barite $\left(\mathrm{BaSO}_{4}\right)$ & $\mathrm{g}$ & Weighting agent & 515.05 \\
Deflocculants & $\mathrm{g}$ & Prevent flocculation and fluid gelation & 0 \\
\hline
\end{tabular}


Table 2 Per cent yield of tannins extracted with different solvents

\begin{tabular}{lllll}
\hline Properties & Solvent $(\mathrm{ml})$ & $\begin{array}{l}\text { Tannins } \\
\text { extracted } \\
(\mathrm{g})\end{array}$ & $\begin{array}{l}\text { Per cent tan- } \\
\text { nins extracted } \\
(\%)\end{array}$ & $\begin{array}{l}\text { Average tan- } \\
\text { nins extracted } \\
(\%)\end{array}$ \\
\hline Acetone & 10 & 0.76 & 3.14 & 3.07 \\
& 12 & 0.71 & 3.03 & \\
& 14 & 0.69 & 3.04 & \\
Toluene & 19 & 0.11 & 0.47 & 0.41 \\
& 25 & 0.14 & 0.68 & \\
Water & 26 & 0.01 & 0.07 & \\
& 9 & 1.72 & 7.61 & 11.67 \\
& 13 & 3.14 & 12.3 & \\
Methanol & 8 & 3.77 & 15.4 & 11.87 \\
& 11 & 2.71 & 11.4 & \\
& 18 & 2.96 & 11.6 & \\
\hline
\end{tabular}

instrument company, Houston, Texas, USA), was used to measure the HPHT filtrate volume (HPHT FL). The temperature in the heating jacket used was $250{ }^{\circ} \mathrm{F}$, and the test pressure was $500 \mathrm{psi}$ (differential pressure). Thereafter, the filter cake thickness (HPHT FCT) was measured.

\section{Results and discussion}

\section{Extraction of RMTE with different solvents}

Table 2 provides the yields in percentage of extracted RMTE using different solvents (acetone, toluene, water and methanol). It shows that tannin extractions with hot water and methanol produced the best results. Toluene gives the lowest yield of tannins, while acetone shows a slightly better yield over that of the toluene. Acetone and toluene were not considered suitable enough for the tannin extraction because of their lowest yield. Tannin-based RMB waste extraction with methanol shows the highest yield of tannins, and was just only a little fraction greater than that obtained with hot water. However, methanol exposure to the environment can affect human health, giving rise to dizziness, nausea, vomiting, headache, etc. (Arunprabu and Ramanathan 2016). Extraction with hot water is more economical compared to extraction with methanol, as confirmed in several recent investigations (Ghazali et al. 2018a; Vigneswaran et al. 2018; Basyuni et al. 2018). Thus, hot water was selected for the extractions of the RMTE deflocculant because it is safer, less harmful and cost effective.

\section{RMTE characterization analysis}

Tables 3 and 4 show the per cent yields of CTE and HTE extracted with hot water, respectively. Previous researches revealed that tannin extracts from polymers are within the range of $60-80 \%$ for CTE and less than $40 \%$ for HTE (Ghazali et al. 2018a; Arunprabu and Ramanathan 2016). As shown in Table 3, the average yields of tannins extracted from RMB wastes were $72.8 \%$, while those of HTE shown in Table 4 were below $0.2 \%$.

\section{FTIR analysis}

Figure 5 shows the FTIR spectra data of RMTE. The FTIR spectrum confirmed the presence of phenols, alcohols, aromatics, alkanes, alkenes, carboxylic acids, alkenes,
Table 3 The data for condensed tannin extracts (CTE)

\begin{tabular}{lllc}
\hline Weight of Petri-dish & $\begin{array}{l}\text { Weight of Petri-dish } \\
\text { with tannin }\end{array}$ & Tannin residue & Stiasny index (SI) \\
\hline 53.62 & 53.98 & 0.35 & 71.6 \\
48.82 & 49.17 & 0.34 & 68.7 \\
47.43 & 47.82 & 0.39 & 78.3 \\
Total Stiasny index (TSI) & & & 218.6 \\
Average percentage of SI (\%) & & & 72.9 \\
\hline
\end{tabular}

\begin{tabular}{llcc}
\hline Absorbance $(\mathrm{nm})$ & $\begin{array}{l}\text { Sample absorbance } \\
(\mathrm{nm})\end{array}$ & Tannin weight $(\mu \mathrm{g})$ & HTE yield $(\%)$ \\
\hline 0.5010 & 0.1110 & 3.098484848 & 0.155 \\
0.3421 & 0.2669 & 15.13636364 & 0.075 \\
0.2901 & 0.3219 & 19.07575758 & 0.096 \\
Total HTE yield (\%) & & & 0.326 \\
Average HTE yield $(\%)$ & & & 0.109 \\
\hline
\end{tabular}

Table 4 The data for hydrolysable tannin extracts (CTE) 
Fig. 5 FTIR spectra of RMTE

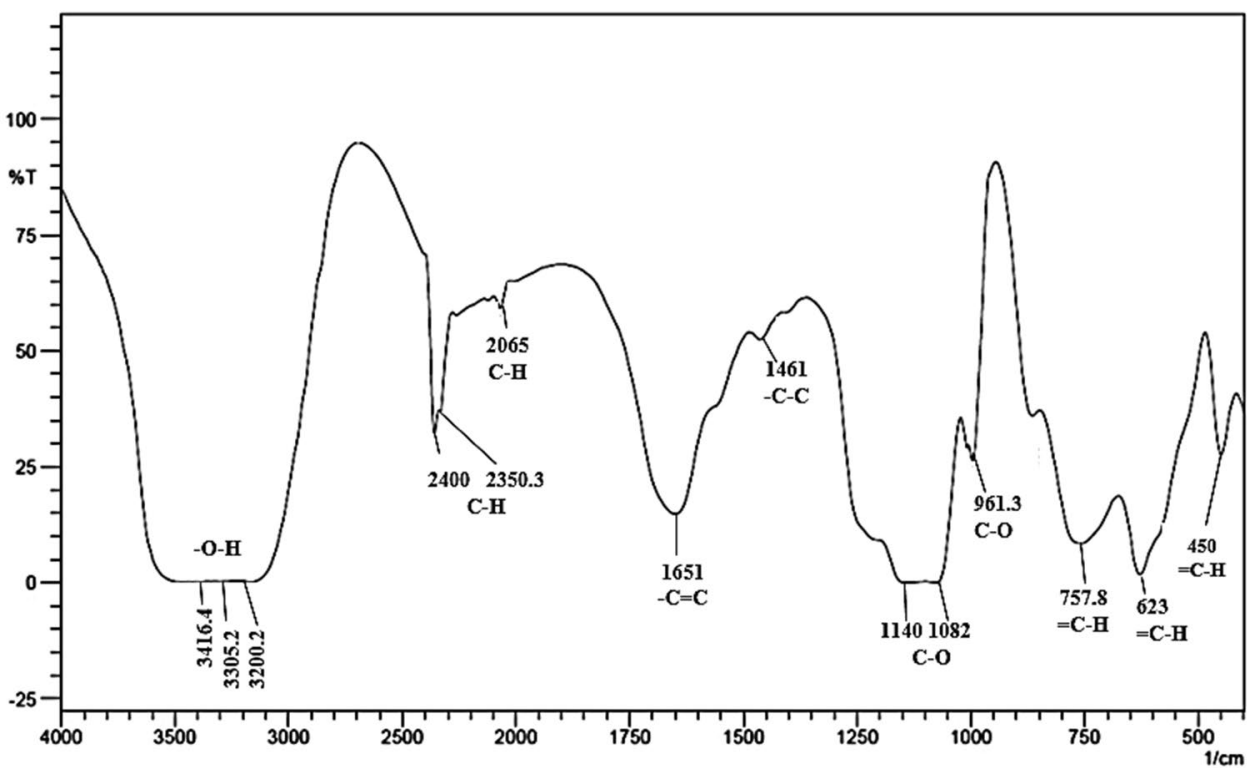

ethers and esters in the RMTE. The bands at $3416.4 \mathrm{~cm}^{-1}$, $3305.2 \mathrm{~cm}^{-1}$ and $3200.2 \mathrm{~cm}^{-1}$ are attributed to the $-\mathrm{OH}$ groups through hydrogen bonding, showing the presence of phenols and alcohols as the interacting functional groups. The bands at $2400 \mathrm{~cm}^{-1}, 2350.3 \mathrm{~cm}^{-1}$ and $2065 \mathrm{~cm}^{-1}$ are ascribed to the stretching vibrations of alkanes $(\mathrm{C}-\mathrm{H})$ groups, while the band at $1651 \mathrm{~cm}^{-1}$ is assigned to the $-\mathrm{C}=\mathrm{C}$ stretching vibrations of alkenes. The band at $1461 \mathrm{~cm}^{-1}$ is attributed to the stretching vibration of aromatic $-\mathrm{C}-\mathrm{C}$ (inrings). The bands at $1140 \mathrm{~cm}^{-1}, 1082 \mathrm{~cm}^{-1}$ and $961.3 \mathrm{~cm}^{-1}$ are assigned to the stretching vibrations of the alcohols, ethers, esters and carboxylic acids $(\mathrm{C}-\mathrm{O})$ groups. The characteristic bands at $757.8 \mathrm{~cm}^{-1}, 623 \mathrm{~cm}^{-1}$ and $450 \mathrm{~cm}^{-1}$ belonged to the $=\mathrm{C}-\mathrm{H}$ bending vibrations of alkenes. Thus, the FTIR spectra confirmed the functional groups in the RMTE deflocculant.

\section{Mud properties evaluation}

\section{Rheology and filtration properties of the base mud}

Table 5 shows the data of the drilling mud formulations for the PV, YP, gel strengths, filtrate volume and the filter cake thickness before and after hot rolling tests under different temperatures. The WBM was formulated to be thick and viscous to replicate gelation behaviour. According to the data shown in Table 5, the rheological properties of the drilling mud systems do not significantly change under different temperatures. The behaviour is comparable
Table 5 Formulated WBM properties before and after hot rolling tests

\begin{tabular}{|c|c|c|c|c|c|c|c|c|c|}
\hline \multirow[t]{2}{*}{ Properties } & \multirow[t]{2}{*}{ Units } & \multicolumn{4}{|c|}{ Before hot rolling $\left({ }^{\circ} \mathrm{F}\right)$} & \multicolumn{4}{|c|}{ After hot rolling $\left({ }^{\circ} \mathrm{F}\right)$} \\
\hline & & 225 & 250 & 275 & 300 & 225 & 250 & 275 & 300 \\
\hline$\theta_{600}$ & $\mathrm{lb} / 100 \mathrm{ft}^{2}$ & 121 & 118 & 113 & 109 & 114 & 110 & 103 & 98 \\
\hline$\theta_{300}$ & $\mathrm{lb} / 100 \mathrm{ft}^{2}$ & 82 & 80 & 77 & 74 & 78 & 75 & 70 & 67 \\
\hline$\theta_{200}$ & $\mathrm{lb} / 100 \mathrm{ft}^{2}$ & 74 & 70 & 68 & 67 & 65 & 63 & 60 & 57 \\
\hline$\theta_{100}$ & $\mathrm{lb} / 100 \mathrm{ft}^{2}$ & 60 & 59 & 57 & 55 & 58 & 55 & 52 & 49 \\
\hline$\theta_{6}$ & $\mathrm{lb} / 100 \mathrm{ft}^{2}$ & 25 & 24 & 21 & 19 & 23 & 22 & 20 & 17 \\
\hline$\theta_{3}$ & $\mathrm{lb} / 100 \mathrm{ft}^{2}$ & 20 & 19 & 17 & 16 & 18 & 17 & 15 & 13 \\
\hline PV & $\mathrm{cP}$ & 39 & 38 & 36 & 35 & 36 & 35 & 33 & 31 \\
\hline YP & $\mathrm{lb} / 100 \mathrm{ft}^{2}$ & 43 & 42 & 41 & 39 & 42 & 40 & 37 & 36 \\
\hline Initial GS & $\mathrm{lb} / 100 \mathrm{ft}^{2}$ & 9 & 8.5 & 8.1 & 7.8 & 8.7 & 8.5 & 8.4 & 8.2 \\
\hline 10-min GS & $\mathrm{lb} / 100 \mathrm{ft}^{2}$ & 30.7 & 29.5 & 29.4 & 29.1 & 28.8 & 28 & 27.5 & 27.3 \\
\hline API FL & $\mathrm{ml}$ & 18.7 & 18.9 & 19.1 & 19.8 & - & - & - & - \\
\hline HPHT FL & $\mathrm{ml}$ & - & - & - & - & 31.2 & 32.4 & 33.8 & 34.1 \\
\hline HPHT FCT & $\mathrm{mm}$ & - & - & - & - & 5.1 & 5.5 & 5.7 & 5.8 \\
\hline
\end{tabular}


at all temperatures. However, the drilling mud PVs, YPs and gel strengths decreased with the increased temperature before hot-rolling treatment. This behaviour is similar to the observed trend of the Viscometer dial readings measured from $600 \mathrm{rpm}$ to $3 \mathrm{rpm}$ from the shear rate of 5.11-1021 $(1 / s)$. Temperature effect is a crucial factor in determining the stability and suitability of drilling fluid properties. This is because of bentonite flocculation at higher temperature exceeding $250{ }^{\circ} \mathrm{F}$. These effects reduced fluid viscosity and increased drilling fluid loss (Oseh et al. 2019b). The PVs, YPs and gel strengths of the base mud decreased under different temperatures after hot-rolling treatment, which is due to the weakening of intermolecular attractive forces holding the mud particles together (Aftab et al. 2016; Oseh et al. 2019b). The decreases were not large enough to affect the performance of the WBMs, which is due to the temperature resistance of bentonite particles up to about $250^{\circ} \mathrm{F}$ (Amani et al. 2012).

The performance of filtration control additives in reducing filtrate loss volume is dictated by the behaviour of the fluid viscosity. The filtrate loss volume increased with increased temperature before and after hot rolling tests. The increase in the API filtrate volume was minimal under different temperatures before hot-rolling treatment. The minimal increase is due to the good temperature resistance of the mud particles (Aftab et al. 2016; Saboori et al. 2018). Increased temperature has the effect of reducing the viscosity of the liquid phase and hence increasing filtration ( $\mathrm{Li}$ et al. 2015; Oseh et al. 2019a, b). The mud samples showed higher values in the filtrate loss volume under the HPHT conditions compared with the API conditions. For example, at $50{ }^{\circ} \mathrm{C}$, the API filtrate volume $(18.7 \mathrm{ml})$ increased to $31.2 \mathrm{ml}$ measured under HPHT conditions by $66.8 \%$. The data of both the API and HPHT FL under different temperatures are reasonably high, indicating high seepage of drilling fluids (Chilingarian and Vorabutr 1983; Mao et al. 2015). A possible reason is because of the sodium ion $\left(\mathrm{Na}^{+}\right)$flocculation in the drilling mud. Sodium $(\mathrm{Na})$ is a monovalent cation and can interact in a charge-deficient environment in such a way that its dispersion in water can cause separated layers of clay particles (Aftab et al. 2016; Oseh et al. 2019b). The HPHT FCT under four different temperatures after hot rolling increases slightly and is within the operating range under high-temperature conditions (API RB 13B-1 2017).

\section{Effects of MDT and RMTE on the properties of the base mud before hot rolling}

\section{Effect on plastic viscosity}

Figure $6 a$ and $b$ shows the effect of MDT and RMTE deflocculants on the PV of the WBM under different temperatures, respectively. The PVs of the WBM containing concentration of MDT and RMTE were significantly decreased with increasing concentration. The PVs related to the two deflocculants are very much comparable. However, the locally derived deflocculant showed lower PVs compared to the commercial Desco deflocculant, which implies that the circulation of drilling mud can be more effective with the use of RMTE deflocculant without causing much frictional pressure in a drilling situation (Ghazali et al. 2018a, b). Increasing temperature does not strongly affect the deflocculating characteristic of the thinners, as increases with the concentration of both the MDT and RMTE thinners provide good and similar thinning effects. For example, with a concentration of $4 \mathrm{~g}$ measured at $250^{\circ} \mathrm{F}$, the PV of the WBM reduced for $38 \mathrm{cP}$ to $25 \mathrm{cP}$ by $36.8 \%$ and to $23 \mathrm{cP}$ by $39.5 \%$ with MDT and RMTE deflocculants, respectively. Measurement taken with the same concentration at $275^{\circ} \mathrm{F}$ also showed a decreased in the PV of the WBM from $36 \mathrm{cP}$ to $24 \mathrm{cP}$ by $33.3 \%$ with MDT deflocculant and to $22 \mathrm{cP}$ by $38.9 \%$ with RMTE deflocculant. Going further to $300^{\circ} \mathrm{F}$ with $8 \mathrm{~g}$ concentration, the PV of the WBM reduced by $45.7 \%$ and $57.1 \%$ when the Desco and locally derived deflocculants
Fig. 6 Plastic viscosity of a MDT and b RMTE at different temperatures

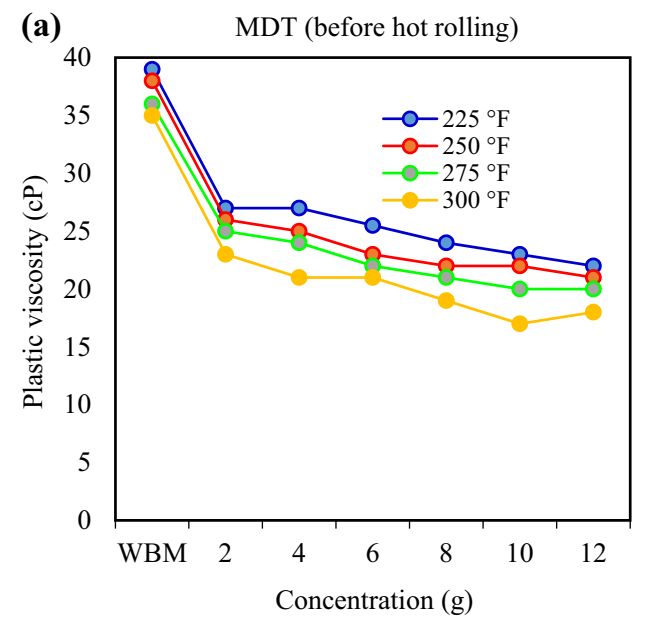

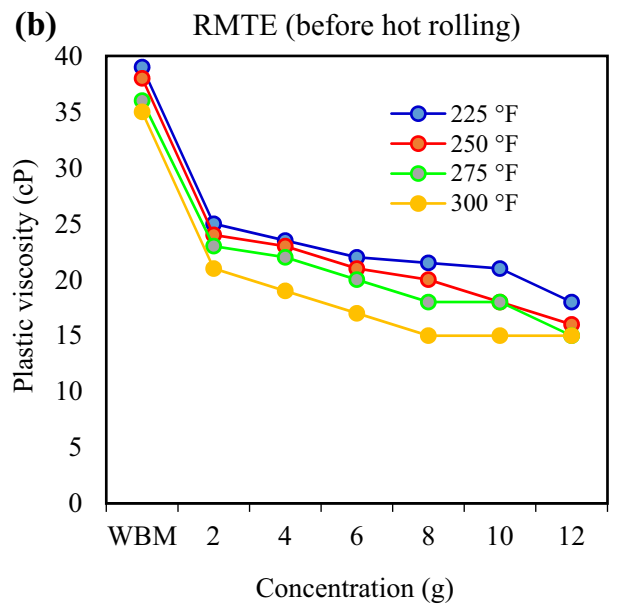

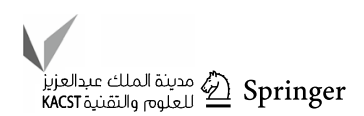


were introduced into the WBM. It can be suggested that the mechanism by which the industrial-grade Desco and the designed RMTE functions in thinning the PVs of the base mud is by thinning the clay particles present in the mud. This was achieved through adsorption of the deflocculants on the positively charged edges of the clay platelets, such as bentonite clay (Moslemizadeh et al. 2015; Oseh et al. $2019 b$ ). The adsorption causes repulsion which reduces the friction between clay platelets, thereby leading to decrease in viscosity (Elochukwu et al. 2017). The WBMs were also deflocculated by the contributions of the plugging characteristic of the deflocculants. The MDT and RMTE were able to increase the solid distributions in the WBM systems by deflocculating clays and barite solids in the mud through the hydrogen bond. Through their colloidal nature, they skewed the size distribution of the particles of higher values. This action increases the thinning ability of the deflocculants (Ghazali et al. 2018a).

\section{Effect on yield point}

Figure 7a, $b$ shows the effect of MDT and RMTE deflocculants on the YPs of WBMs, respectively. Deflocculants are typically needed in a mud system to reduce the linking of clay layers by adsorbing onto the clay positive charged edges (Oseh et al. 2019a, b). As Fig. 7 shows, increase in concentration of MDT deflocculant reduces the YPs of the base mud with increasing temperature. With a concentration of $2 \mathrm{~g}$, the YP of the WBM at $225^{\circ} \mathrm{F}$ reduced by half $\left(21 \mathrm{lb} / 100 \mathrm{ft}^{2}\right)$ of its initial value using commercial MDT deflocculant. By the same condition, the YP of the base mud decreased by $57.1 \%$ of its initial value with the RMTE deflocculant. With increasing temperatures of the thinners, the YPs of the base mud decreased with a concentration range between 2 and $8 \mathrm{~g}$, and these effects extend to $12 \mathrm{~g}$ with the Desco deflocculant. However, after the addition of $10 \mathrm{~g}$ and $12 \mathrm{~g}$ of RMTE deflocculant, the YPs of the base mud started to increase with increasing temperature for all the temperature conditions. Thinning performance of the deflocculants up to $8 \mathrm{~g}$ indicates a better performance with the RMTE. This portends that $8 \mathrm{~g}$ concentration is the optimum deflocculating ability of the RMTE. As shown in Fig. 7b, beyond the 8-g concentration, the RMTE was no longer capable of neutralizing the positive charges on the clay edges as well as preventing clay layers from building a consolidated network (Moslemizadeh et al. 2016; Oseh et al. 2019b). Overall, the extracted RMTE indicates good thinning characteristics as it matched the commercial Desco deflocculant up to 8-g concentration. These data indicate stronger thinning ability with the use of RMTE at a lower concentration compared with MDT, which is beneficial for drilling economics.

\section{Effect on gel strength}

Figures 8 and 9 show the data on the initial and 10-min GS of the two studied deflocculants under different temperatures, respectively. The data show significant reduction in the initial (Fig. 8) and 10 min (Fig. 9) gel strengths of the WBM with the Desco and RMTE deflocculants. They vary slightly with changes in temperature and they exhibited "low-flat gels", which is very much desirable and preferable in drilling operation to "high-flat gels" and "high gel strength". "Lowflat gels" can mitigate the propensity of stuck pipe incident, while high GS and 'high-flat gels' need greater pumping to resume fluids circulation and are therefore undesirable for drilling operation (Caenn et al. 2017; Oseh et al. 2019b). From the observed trends, mud samples pertaining to the RMTE indicate lower gel strength at all temperatures compared to those of the MDT.

According to the previous investigations (Moslemizadeh et al. 2015; Neshat and Shadizadeh 2016; Ghazali et al. 2018a; Oseh et al. 2019a, b), the mechanism of deflocculant is mainly on their capacity to separate individual unit
Fig. 7 Yield point of a MDT and b RMTE at different temperatures

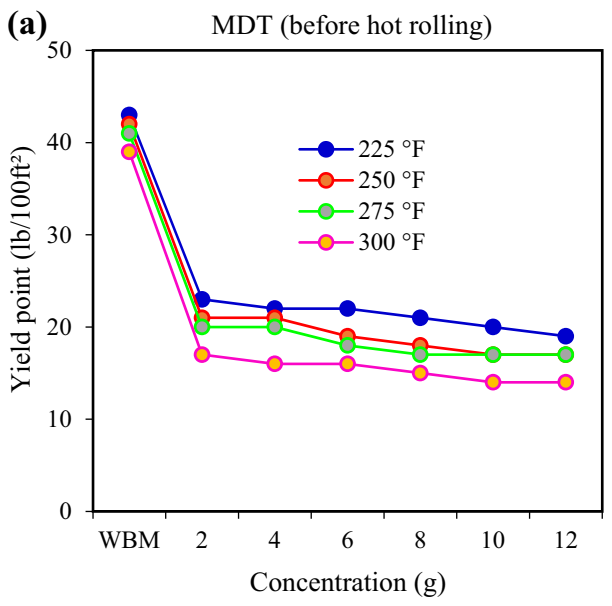

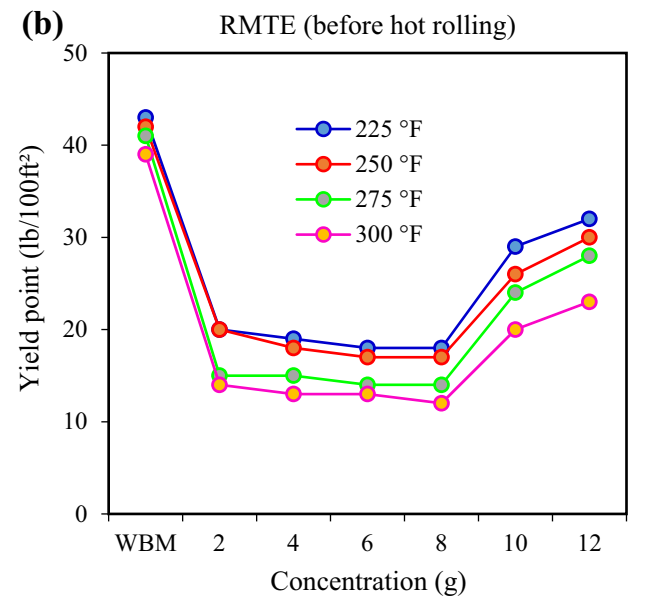


Fig. 8 Initial gel strength of a MDT and $\mathbf{b}$ RMTE at different temperatures
Fig. 9 10-min gel strength of a MDT and $\mathbf{b}$ RMTE at different temperatures
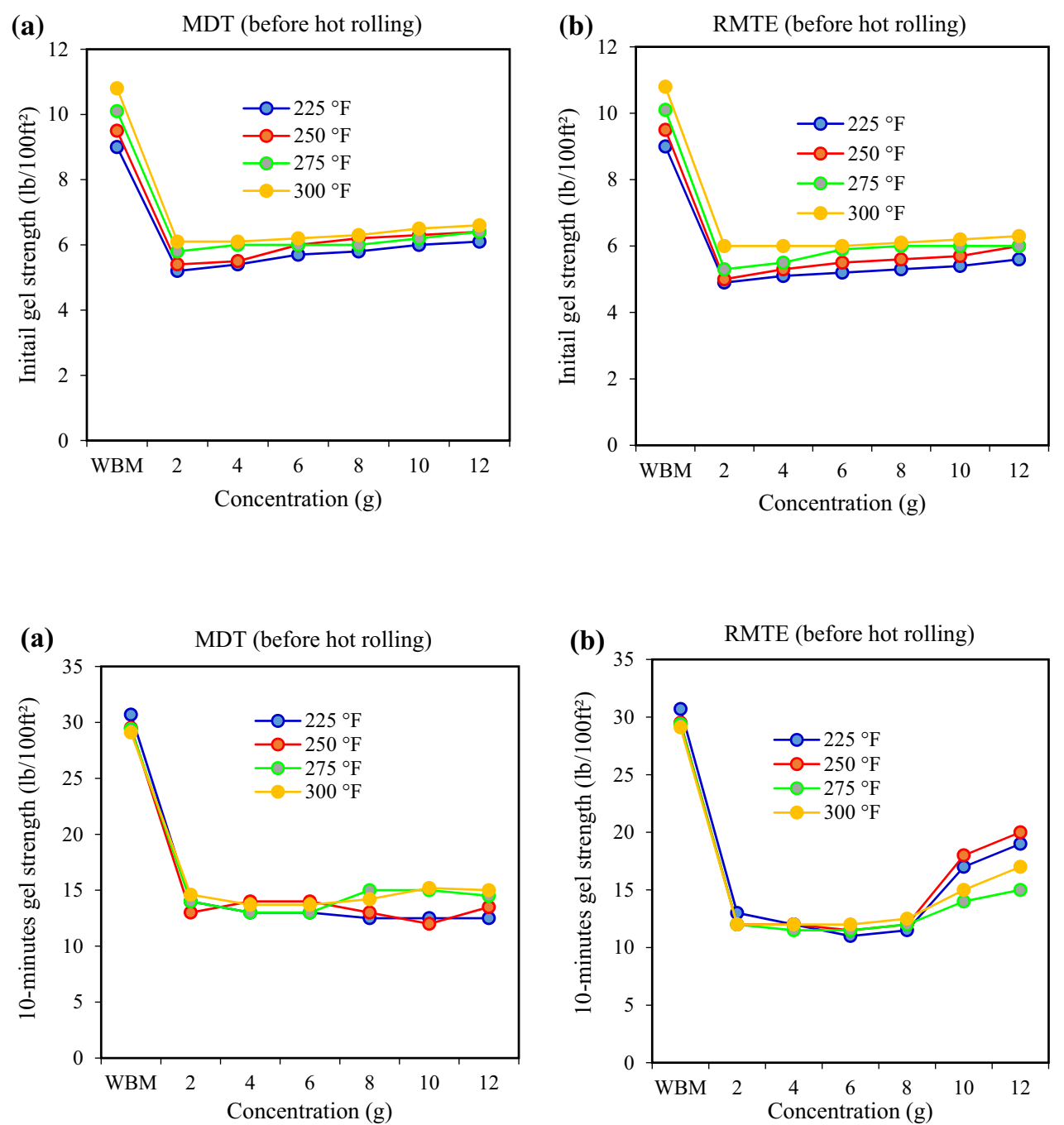

layers of clay platelets from linking together by adsorbing onto the positive charged edges of the clay platelets. This adsorption prevents the formation of a strong network leading to decrease in PV and subsequently, the reduction in the gelation of the drilling mud. As observed in the YP of the base mud with RMTE deflocculant at concentrations above $8 \mathrm{~g}$ (Fig. 7b), the same phenomenon was observed with 10-min gel strength of the base mud with RMTE for all temperature conditions (Fig. 9b). The thinning effect of the drilling mud formulations was lower with the RMTE compared to that of the MDT before the 8-g concentration. For example, at $250^{\circ} \mathrm{F}$ using $8 \mathrm{~g}$ concentration, the MDT decreased the 10-min GS of the WBM by $55.9 \%$, while the RMTE demonstrate 59.3\% thinning. After $8 \mathrm{~g}$, further addition of the RMTE increases the gelling of the base mud with increasing concentration. At $250^{\circ} \mathrm{F}$, the GS of the base mud with RMTE reduces by $32.2 \%$, while the MDT demonstrates higher reduction by $54.2 \%$, confirming the similar behaviour of the YP and 10-min GS by both deflocculants. This further validates that the RMTE deflocculant will be more efficient with a concentration of $8 \mathrm{~g}$ in conventional WBM under the same studied conditions.

\section{Effect on filtration properties}

Figure 10a, b shows the data on the API filtrate volume of the two studied deflocculants under different temperatures. The filtrate volume of the mud samples was slightly better controlled with the RMTE deflocculant. The filtrate volume of the WBM significantly decreased with increasing concentration of the MDT and RMTE deflocculants. However, it also minimally rises with increasing temperature, owing to the ability of the energized liquid particles to move more freely (Oseh et al. 2019b). With 8-g concentration, the MDT and RMTE at $300^{\circ} \mathrm{F}$ hugely reduced the API FL of the base mud samples by $62.3 \%$ and $63.1 \%$, respectively, indicating that the locally derived RMTE is comparable with the 
Fig. 10 API filtrate volume of $\mathbf{a}$ MDT and $\mathbf{b}$ RMTE mud samples
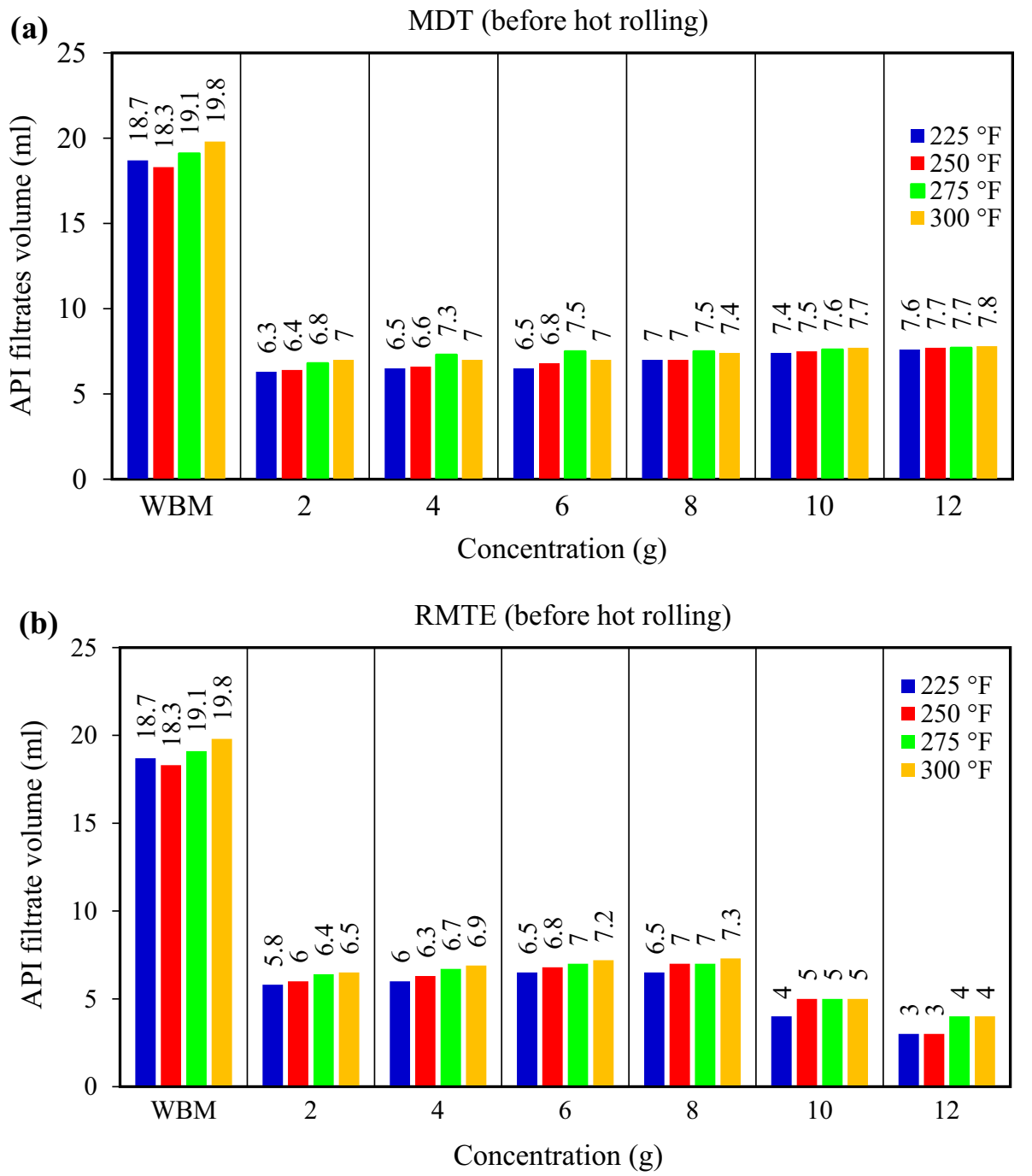

commercial Desco. After $8 \mathrm{~g}$ addition, the WBM containing the RMTE showed better filtrate control with increasing concentration and temperature compared to that of the MDT.

As shown in Fig. 10, the thinning property of the two drilling muds was very efficient. They effectively decreased the filtrate volume of the base mud at all temperature conditions. FTIR test data earlier indicated that Rhizophora Mucronata has active - $\mathrm{OH}$ groups in their network. Because of the presence of the hydrogen bond, the newly designed RMTE adsorbed onto the positive charged edges of the clay platelets to neutralize the positive charges, thereby causing a decrease in filtrate loss volume (Oseh et al. 2019b). In addition, the RMTE deflocculant has a good wall-building property, due to its ability to skew the particle size of clays to become uniform (Ghazali et al. 2018a, b).

\section{Temperature resistance of drilling mud formulations}

Figures 11, 12, 13 and 14 show the temperature resistance on the PV, YP, GS and HPHT filtration properties of the formulated drilling muds. Comparing the mud system's behaviour before hot rolling tests (Figs. 6, 7, 8, 9, 10) and after hot rolling tests (Figs. 11, 12,13,14), the drilling mud properties were not significantly affected by the concentrations of $2 \mathrm{~g}$, $8 \mathrm{~g}$ and $12 \mathrm{~g}$ each of MDT and RMTE in WBM systems. The three concentrations for all measured temperatures indicate significant changes in the rheological properties compared with the WBM.

As Fig. 11 shows, the concentration of $2 \mathrm{~g}$ at $225^{\circ} \mathrm{F}$ decreased the PV of the base mud by $31.4 \%$ by using MDT and by $37.1 \%$ with the RMTE, indicating a better thinning effect by the RMTE over the MDT. Referring to Fig. 6 before hot rolling test, at the same concentration and temperature, the thinning ability of the MDT and RMTE on the PV of the base mud was $30.8 \%$ and $35.9 \%$, respectively. As 
Fig. 11 Effect of temperature on plastic viscosity of MDT and RMTE mud samples
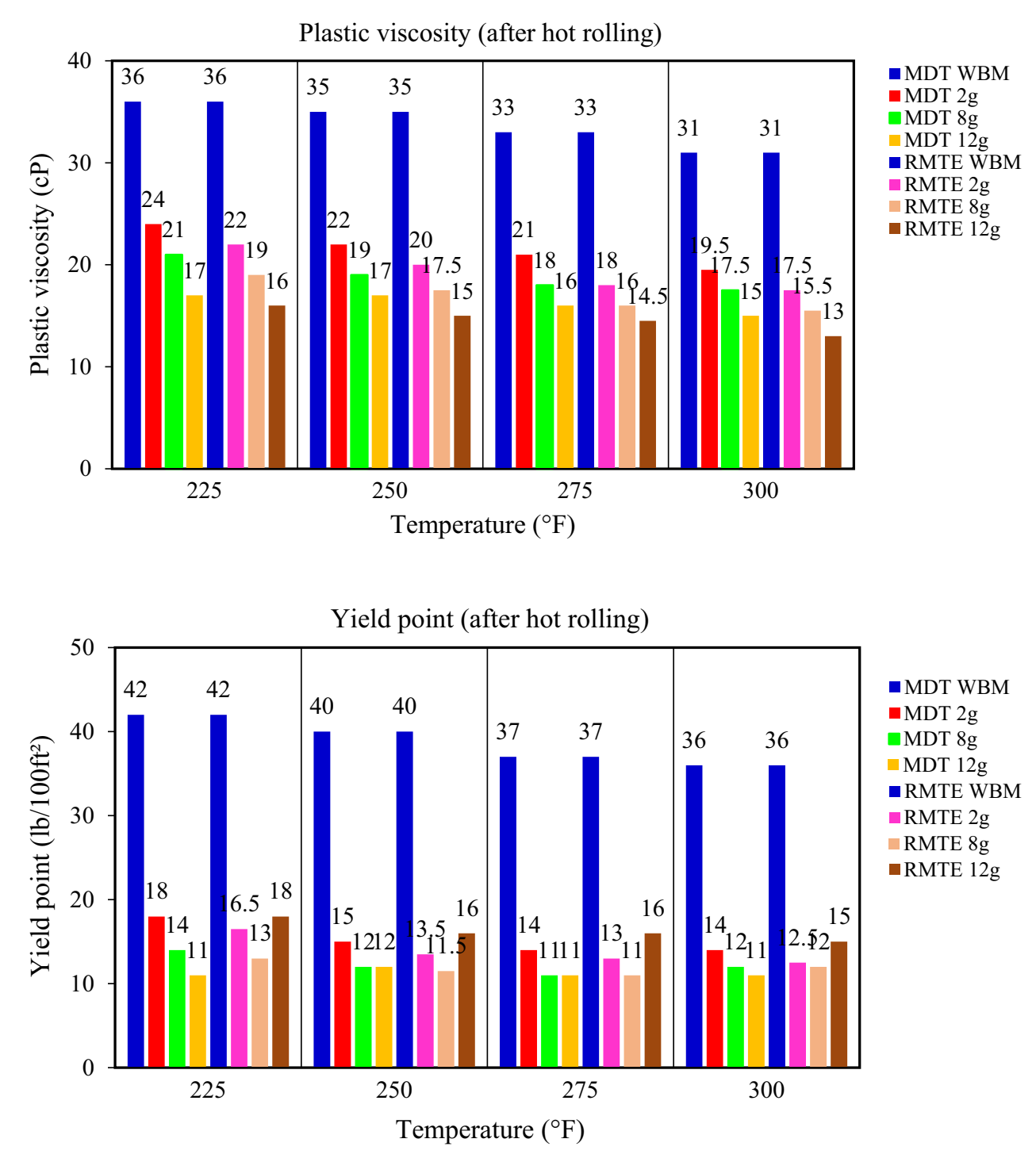

Fig. 12 Effect of temperature on yield point of MDT and RMTE mud samples observed from the PV data, the mud samples after hot rolling tests compared favourably with those obtained before heating, which is indicative of the good thermal stability of both deflocculants with changing temperature. RMTE deflocculant displayed a better reduction in PV compared with the Desco before and after hot rolling tests.

As Fig. 12 shows, the locally sourced tannin has comparable YP with the commercial Desco at all temperatures. The formulated base mud with the deflocculants significantly decreased the YP with increasing concentration at all temperatures. At $8 \mathrm{~g}$ of the deflocculants at high temperature of $300{ }^{\circ} \mathrm{F}$, the YP of the base mud decreased in the same value of $66.7 \%$. These results are similar to the trend of YP observed for both MDT and RMTE before hot rolling tests. The Desco achieved a better thinning effect of the YP of the base mud at $12 \mathrm{~g}$ over that of the RMTE. The two deflocculants showed good temperature resistance, but a higher thinning effect of the WBM was observed after hot rolling tests compared to that observed before hot rolling tests. The increased YP data for the RMTE after $8 \mathrm{~g}$ concentration further demonstrate it to be its optimal thinning capacity. The more distance created among the clay particles after hot rolling due to the $-\mathrm{OH}$ groups neutralization of the positive charges on the clay edges was the reason for their inability to effectively link together to form a stronger network structure (Annis and Smith 1996; Oseh et al. 2019b). This has helped to reduce the yield point of the base mud.

It can be observed from the initial and 10-min GS data that the two deflocculants decreased the gelation effect of the base mud (Fig. 13). The initial GS of the WBMs is within the decreasing range of $8.7-8.2 \mathrm{lb} / 100 \mathrm{ft}^{2}$ for the different temperature conditions. These values decreased to the range of $5.1-6.3 \mathrm{lb} / 100 \mathrm{ft}^{2}$ by the MDT and to the range of 4.7-6.4 lb/100ft ${ }^{2}$ by the RMTE (Fig. 13a). The deflocculants show similar initial gel strength trends by increasing with

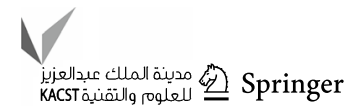


Fig. 13 Effect of temperature on a initial and b 10-min gel strength of MDT and RMTE mud samples

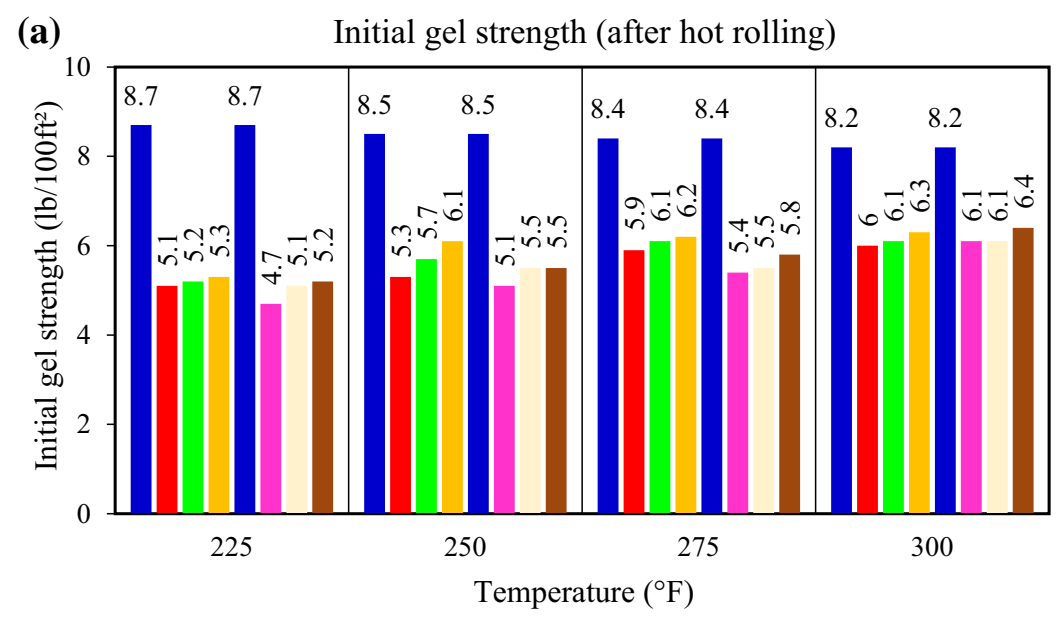

- MDT WBM

- MDT $2 \mathrm{~g}$

MDT $8 \mathrm{~g}$

MDT $12 \mathrm{~g}$

- RMTE WBM

- RMTE $2 \mathrm{~g}$

RMTE 8g

- RMTE $12 \mathrm{~g}$

(b) 10 minutes gel strength (after hot rolling)

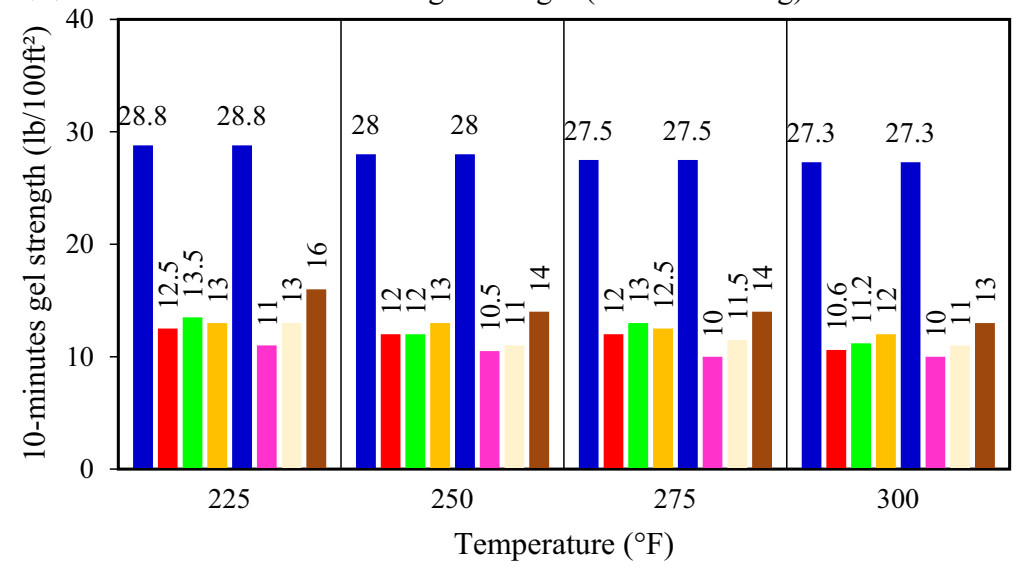

- MDT WBM

- MDT $2 \mathrm{~g}$

MDT $8 \mathrm{~g}$

MDT $12 \mathrm{~g}$

- RMTE WBM

- RMTE $2 \mathrm{~g}$

$\square$ RMTE $8 \mathrm{~g}$

- RMTE $12 \mathrm{~g}$

increasing concentration and temperatures, which is unlike that of the base mud at the decreasing trend with temperature. The effect of the deflocculants on the gel strength of the WBM was significantly higher for 10-min GS compared with the initial GS (Fig. 13b). The 10-min gel strength of the WBM was significantly reduced by the MDT to the range of $13.5-12 \mathrm{lb} / 100 \mathrm{ft}^{2}$ and to the range of $16-10 \mathrm{lb} / 100 \mathrm{ft}^{2}$ by the RMTE at increasing temperature.

Just like the data of the initial GS after hot rolling test, the RMTE has a good comparison with the MDT in deflocculating the 10-min GS of the base mud. The mud samples with $2 \mathrm{~g}, 8 \mathrm{~g}$ and $12 \mathrm{~g}$ concentrations of the deflocculants oven-rolled for $16 \mathrm{~h}$ do not affect much their thermal stability. As mentioned earlier, the RMTE deflocculant disrupts any formation of strong gel networks by the clay platelets, owing to the neutralization of the positive charges on clay edges. These phenomena contribute to reducing the gelation of the WBM (Li et al. 2015; Ghazali et al. 2018b; Oseh et al. 2019b).

Figure 14 shows the HPHT FL and FCT of the base mud systems with MDT and RMTE. The HPHT FL of the base mud after hot rolling test was within the range of 31.2-34.1 $\mathrm{ml}$, and it was higher than the API FL before hot rolling test. Filtration control properties of conventional WBM greatly depend on the performance of colloidal properties present in the mud (Mao et al. 2015). With $2 \mathrm{~g}, 8 \mathrm{~g}$ and $12 \mathrm{~g}$ concentrations of MDT (Fig. 14a) and RMTE (Fig. 14b), the filtrate volume of the base mud reduced to the range of 15-14 $\mathrm{ml}$ and 14-10 $\mathrm{ml}$ with MDT and RMTE, respectively. The RMTE deflocculant showed good filtration control capacity, which is a little better than that of the MDT. With a concentration of $8 \mathrm{~g}$ at $275^{\circ} \mathrm{F}$, MDT reduced the filtrate volume of the base mud by $56.8 \%$, while RMTE showed a higher reduction of $63.6 \%$. A similar trend was observed at the same concentration at $300{ }^{\circ} \mathrm{F}$, where the filtrate loss volume of the base mud with MDT decreased by $56.0 \%$, and $63.6 \%$ reduction was demonstrated by the RMTE. These data further typify the better thinning effect of the RMTE over the Desco deflocculant.

The more the filtrate loss into the formation, the more the thickness of the filter cake (Oseh et al. 2019c). Figure 14b shows comparable HPHT filter cake thickness of both 
Fig. 14 HPHT filtration properties of $\mathbf{a}$ MDT and $\mathbf{b}$ RMTE mud samples

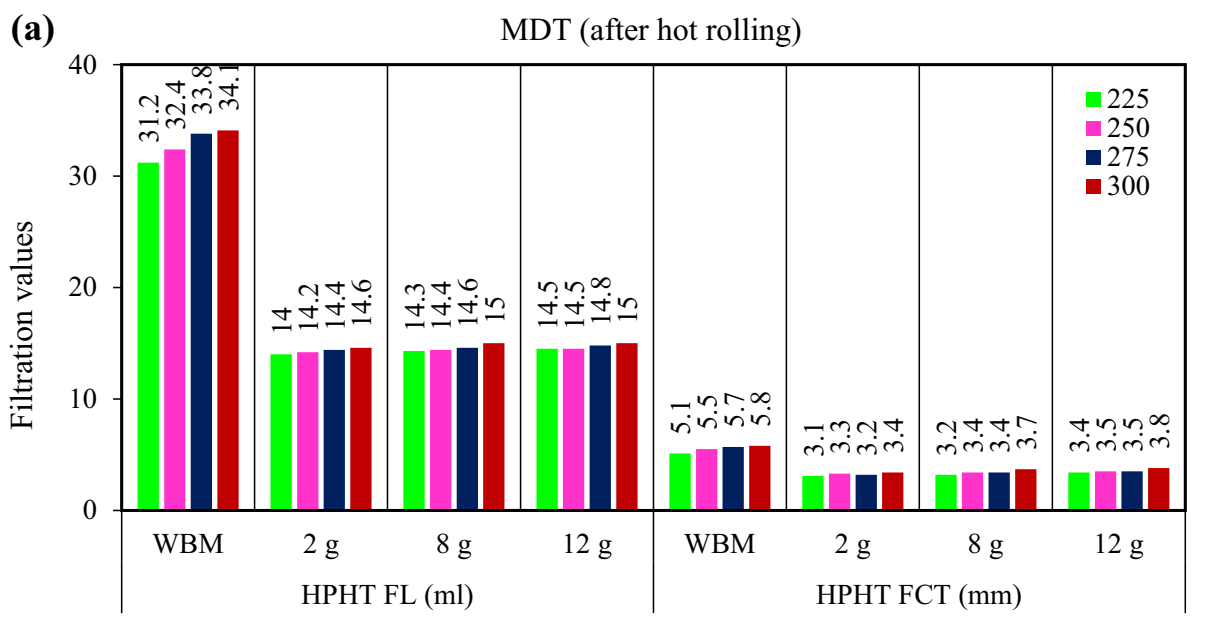

Filtration properties

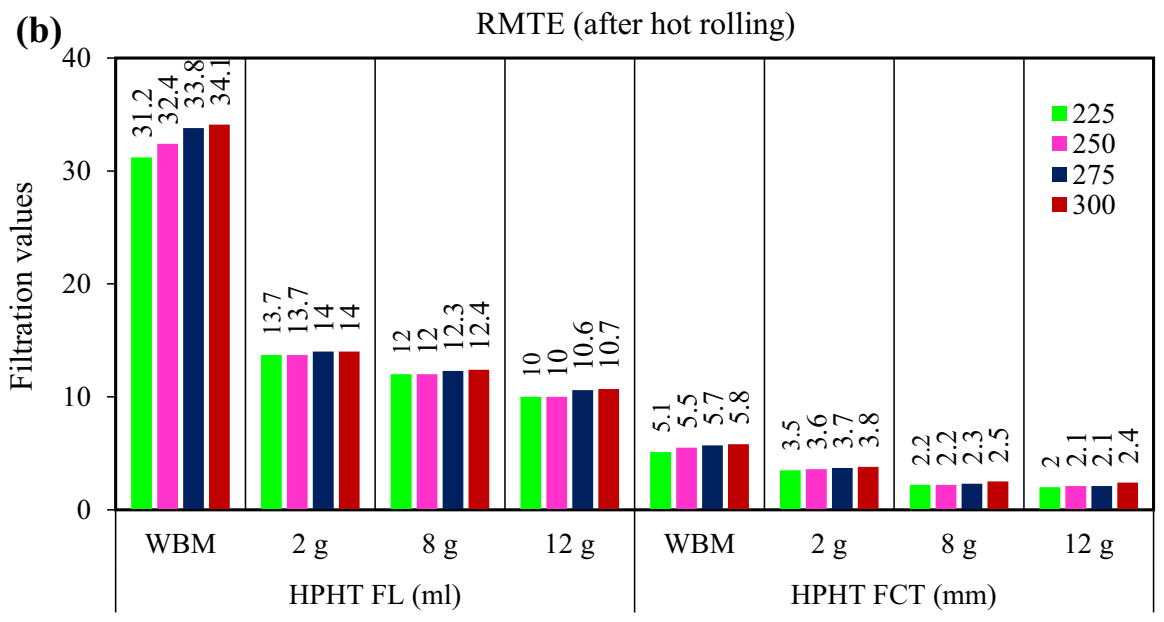

Filtration properties deflocculants. The HPHT FCT of the base mud increased with increasing temperature in the range of $5.1-5.8 \mathrm{~mm}$. The data authenticate the lower cake thickness of the base mud with the locally derived tannin compared with the commercial Desco. The HPHT FL after hot rolling test is within the API recommendations for drilling fluid under HPHT conditions (API RB 13B-2 2017). These data in Fig. 14 indicate RMTE to be more effective in minimizing filtrate flux compared to Desco. It can therefore be suggested that the addition of RMTE more improved the filtration control of the base mud and hence the lower filter cake thickness. The overall outcomes of the tests illustrate that RMTE stands a chance of being one of the technically, low-cost and environmentally viable replacements for the industrial-grade Desco deflocculant, mostly for the higher cost and least safe of the Desco deflocculant.

\section{Conclusions}

The following conclusions are drawn from this study:

1. A tannin-based deflocculant derived from Rhizophora mucronata bark wastes was effectively extracted using hot water solvent, and FTIR test indicates that the extracted RMTE contains different functional groups including $-\mathrm{OH}$ groups, which was responsible for its mud's thinning ability.

2. The RMTE has comparable drilling fluid properties to that of the commercial Desco, but its application for drilling fluid should be limited to $8 \mathrm{~g}$ concentration under the same working conditions, where it shows better deflocculating performance than the commercial Desco.

3. The newly designed RMTE deflocculant was compatible with high-temperature conditions, and it has good

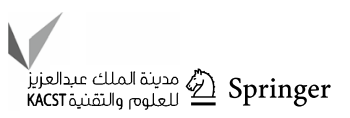


temperature resistance. Therefore, more attention should be directed to the use of locally derived tannins for the formulation of WBMs instead of commercial Desco, mostly for their low cost and ecological approval.

Acknowledgements The authors wish to thank the Research Management Centre of UTM by providing the research grant (vote no. Q. J130000.2646.13J77) and the Malaysian Ministry of Higher Learning for their support.

\section{Compliance with ethical standards}

Conflict of interest On behalf of all the authors, the corresponding author states that there is no conflict of interest.

Open Access This article is distributed under the terms of the Creative Commons Attribution 4.0 International License (http://creativeco mmons.org/licenses/by/4.0/), which permits unrestricted use, distribution, and reproduction in any medium, provided you give appropriate credit to the original author(s) and the source, provide a link to the Creative Commons license, and indicate if changes were made.

\section{References}

Abu-Jdayil B (2011) Rheology of sodium and calcium bentonite-water dispersions: effect of electrolytes and aging time. Int J Miner Process 98(3):208-213

Afidah AR (2005) Physico-chemical characterization of mangrove tannins as corrosion inhibitors. Ph.D. Thesis, Universiti Sains Malaysia

Aftab A, Ismail AR, Khokhar S, Ibupoto ZH (2016) Novel zinc oxide nanoparticles deposited acrylamide composite used for enhancing the performance of water-based drilling fluids at elevated temperature conditions. J Pet Sci Eng 146:1142-1157

Altun G, Osgouei AE, Ozyurtkan MH, Serpen U (2015) Sepiolite based muds as an alternate drilling fluid for hot environments. World Geotherm Congr 10:12-21

Amani M, AL-Jubouri M, Shadravan A (2012) Comparative study of using oil-based mud versus water-based mud in HPHT fields. Adv Pet Explor Dev 4(2):18-27

American Petroleum Institute 13B-1 (2017) Recommended practice for field testing water-based drilling fluids, 5th edn, pp 1-121

Annis MR, Smith V (1996) Drilling fluids technology. Exxon Company, Irving

Arunprabu PD, Ramanathan T (2016) antimicrobial activity of crude methanolic extracts of Rhizophora mucronata spp. IJSIT 5(6):520-527

Barry MM, Jung YS, Lee JK, Phuoc TX, Chyu MK (2015) Fluid filtration and rheological properties of nanoparticle additive and intercalated clay hybrid bentonite drilling fluids. J Petrol Sci Eng. 127:338-346. https://doi.org/10.1016/j.petrol.2015.01.012

Basyuni M et al (2018) IOP conference seminar: evaluation of Rhizophora mucronata growth at first-year mangrove restoration at Abandoned Ponds, Langkat, North Sumatra. Earth Environ Sci 126:012118

Boyou NV, Ismail I, Sulaiman WRW, Haddad AS, Husein N, Hui HT, Nadaraja K (2019) Experimental investigation of hole cleaning in directional drilling by using nano-enhanced water-based drilling fluids. J Pet Sci Eng 176:220-231
Caenn R, Darley HCH, Gray GR (2017) Introduction to drilling fluids. In: Composition and properties of drilling and completion fluids, 7 th edn. Gulf Professional Publishing, USA, pp 1-748. ISBN: 978-0-12-804751-4

Chilingarian GV, Vorabutr P (1983) Drilling and drilling fluids. Elsevier, Amsterdam, Netherlands 37 50:149-151

Choo KY, Bai K (2015) Effects of bentonite concentration and solution $\mathrm{pH}$ on the rheological properties and long-term stabilities of bentonite suspensions. Appl Clay Sci 108:82-190

Elgailani IEH, Ishak CY (2016) Methods for extraction and characterization of tannins from some Acacia species of Sudan. Pak J Anal Environ Chem 17(1):43-49

Elochukwu H, Gholami R, Dol SS (2017) An approach to improve the cuttings carrying capacity of nanosilica based muds. J Petrol Sci Eng 52:10-216

Fujii R (2017) Hundred years' history of challenge to shale inhibition. J Jpn Assoc Pet Technol 82(5):332-345

Gaugler M, Grigsby WJ (2009) Thermal degradation of condensed tannins from Radiata Pink Bark. J Wood Chem Technol 29(4):305-321

Ghazali NA, Naganawa S, Masuda Y (2018a) Development of modified Rhizophora tannin biopolymer additive in drilling fluid system for high temperature well applications. Soc Pet Eng. https://doi. org/10.2118/191080-ms

Ghazali NA, Naganawa S, Masuda Y (2018b) Feasibility study of tannin-lignosulfonate drilling fluid system for drilling geothermal prospect. In: SGP-TR-213 Proceedings, 43rd workshop on geothermal reservoir engineering, 12-14 February, Stanford University, Stanford, CA

Kelessidis VC (2017) Yield stress of bentonite dispersions. Rheology: Open Access 1(1):1-12

Li W, Zhao X, Ji Y, Peng H, Li Y, Liu L, Han Z (2015) An investigation on environmentally friendly biodiesel-based invert emulsion drilling fluid. J Pet Explor Prod Technol. https://doi.org/10.1007/ s13202-015-0205-7

Mahmoud O, Nasr-El-Din HA, Vryzas Z, Kelessidis VC (2017) Characterization of filter cake generated by nanoparticle-based drilling fluid for HP/HT applications. In: SPE international conference on oilfield chemistry, SPE-184572-MS, pp 1-19

Makkar HPS (2003) Determination of hydrolysable tannins (Gallotannins and Ellagitannins) after reaction with potassium iodate. In: Quantification of tannins in tree and shrub foliage, pp 59-61. https://doi.org/10.1007/978-94-017-0273-7_7

Mao H, Qiu Z, Shen Z, Huang W (2015) Hydrophobic associated polymer based silica nanoparticles composite with core-shell structure as a filtrate reducer for drilling fluid at ultra-high temperature. J Petrol Sci Eng 129:1-15

Maricusa M, Hernández A, Enrique RDR et al (2018) Nutrient removal efficiency of Rhizophora mangle (L.) seedlings exposed to experimental dumping of municipal waters. Diversity 10:1623. https://doi.org/10.3390/d10010016

Markom M, Hasan M, Daud WRW, Singh H, Jahim JM (2007) Extraction of hydrolysable tannins from Phyllanthus niruri Linn.: effects of solvents and extraction methods. Sep Purif Technol 52(3):487-496. https://doi.org/10.1016/j.seppu r.2006.06.003

Moslemizadeh A, Shadizadeh SR, Moomenie M (2015) Experimental investigation of the effect of henna extract on the swelling of sodium bentonite in aqueous solution. Appl Clay Sci 105:78-88

Moslemizadeh A, Shadizadeh SR, Moomenie M (2016) A natural dye in water-based drilling fluid: swelling inhibitive characteristics and side effects. Petroleum 3:1-12

Nanthagopal K, Ashok B, Garnepudi RS, Tarun KR, Dhinesh B (2019) Investigation on diethyl ether as an additive with Calophyllum inophyllum biodiesel for CI engine application. Energy Convers Manag 179:104-113 
Negm NA, Tawfik SM, Abdou MI, Badr EA, Ghuiba FM (2015) Evaluation of some nonionic surfactants derived from tannic acid as additives for water-based mud. Egypt J Pet 23(1):7-14

Neshat J, Shadizadeh SR (2016) Evaluation of a naturally-derived deflocculant (Terminalia Chebula) in bentonite dispersions. Iran J Oil Gas Sci Technol 5(2):21-44. https://doi.org/10.22050/ijogs t. 2016.15788

Oseh JO, Gbadamosi AO, Ogunyemi A, Omotara OO (2018) Transports of different cuttings sizes in a wellbore using henna and lignite materials. J Eng Res Dev (AJERD) 3:351-365

Oseh JO, Norddin MNA, Farooq F, Ismail I, Ismail AR, Gbadamosi AO, Agi A (2019a) Experimental investigation of the effect of henna leaf extracts on cuttings transportation in highly deviated and horizontal wells. J Pet Explor Prod Technol. https://doi. org/10.1007/s13202-019-0631-z

Oseh JO, Norddin MNA, Ismail I, Ismail AR, Gbadamosi AO, Agi A (2019b) Effect of the surface charge of entrapped polypropylene at nanosilica-composite on cuttings transport capacity of water-based muds. Appl Nanosci. https://doi.org/10.1007/ s13204-019-01063-9

Oseh JO, Mohd NMNA, Ismail I, Ismail AR, Gbadamosi AO, Agi A, Ogiriki SO (2019c) Investigating almond seed oil as potential biodiesel-based drilling mud. J Pet Sci Eng. https://doi.org/10.1016/j. petrol.2019.106201

Pérez MA, Rengifo R, Pereira C et al (2017) Dividivi tannins: an ecological product for water-based drilling fluids. Environ Dev Sustain 19:1815-1829

Ping L, Pizzi A, Guo ZD, Brosse N (2011) Condensed tannins extraction from grape pomace: characterization and utilization as wood adhesives for wood particleboard. Ind Crops Prod 34(1):907-914

Saboori R, Sabbaghi S, Kalantarias A, Mowla D (2018) Improvement in filtration properties of water-based drilling fluid by nanocarboxymethyl cellulose/polystyrene core-shell nanocomposite. J Pet Explor Prod Technol 8:445-454

Sayindla S, Lund B, Ytrehus JD, Saasen A (2017) Hole-cleaning performance comparison of oil-based and water-based drilling fluids. J Pet Sci Eng 159:49-57

Sukardjo S (1987) Natural regeneration status of commercial mangrove species (Rhizophora Mucronata and Bruguiera gymnorrhirra) in the mangrove forest of Tanjung Bungin, Banyuasan District, South Sumatera. For Ecol Manag 20(3-4):233-252. https://doi. org/10.1016/0378-1127(87)90082-X

Vigneswaran T, Mohamed HSM, Doss A (2018) Determination of in vitro antioxidant activity of leaf extracts of Rhizophora mucronata Lam. (Rhizophoraceae). J Pharmacogn Phytochem 7(5):2251-2255

Wilson MA, Hatcher PG (1988) Detection of tannins in modern and fossil barks in plant residues by high resolution solid-state: Nuclear magnetic resonance. Org Geochem 12(6):539-546. https ://doi.org/10.1016/0146-6380(88)90145-3

Yunitaa P, Irawana S, Kaniab D (2016) Optimization of water-based drilling fluid using non-ionic and anionic surfactant additives. Proc Eng 148:1184-1190

Zhang LM, Dai YY (1999) Novel modified lignosulfonate as drilling mud thinner without environmental concerns. J Appl Polym Sci 74(7):1662-1668

Zhong H, Shen G, Qiu Z, Lin Y, Fan L, Xing X, Li J (2019) Minimizing the HTHP filtration loss of oil-based drilling fluid with swellable polymer microspheres. J Petrol Sci Eng 172:411-424

Publisher's Note Springer Nature remains neutral with regard to jurisdictional claims in published maps and institutional affiliations. 